\title{
Objective measures for functional diagnostic of the upper airways: practical aspects*
}

Cinthia Chaves, Claudia Ribeiro de Andrade, Cassio Ibiapina

Departament of Paediatrics, Faculty of Medicin, Federal University of Minas Gerais, Belo Horizonte - Minas Gerais, Brazil
Rhinology 52: 99-103, 2014

DOl:10.4193/Rhino13.109

*Received for publication:

July 26, 2013

Accepted: September 23, 2013

\section{Summary}

Objective: To review the main papers published on the main available tests to obtain objective values of nasal patency and to demonstrate aspects of their use in medical practice.

Methodology: We performed a non-systematic review of the MEDLINE and LILACS databases, and the most relevant articles were selected.

Results: Objective evaluations are important in epidemiological studies and in monitoring of patients with nasal obstruction. There is a wide variety of objective tests of nasal function; among them acoustic rhinometry, rhinomanometry, and peak nasal inspiratory flow (PNIF) are currently the most used tests.

Conclusion: The choice of the method to evaluate nasal function depends on the conditions of each health service. PNIF has been highlighted as a simple and reliable alternative that provides easy-to-interpret results, and is thus an attractive method for clinical practice.

Key words: nose, medical examination, respiratory function tests, rhinomanometry, acoustic rhinometry

\section{Introduction}

Understanding the physiological aspects and the impact of anatomical and pathological alterations in nasal airflow have long challenged investigators ${ }^{(1)}$. Decisions about medical and surgical interventions in the upper airway can be very difficult. When done separately, rhinoscopy and increasingly more sophisticated image exams do not distinguish between normal and abnormal nasal function ${ }^{(2,3)}$.

Diagnostics for nasal patency that rely solely on the patient's perception are not satisfactory, and the definition of good breathing through the nose is very controversial in the literature ${ }^{(2,4)}$. The use of subjective information on nasal obstruction obtained from standardized and validated questionnaires has not been well accepted and the comparison of such subjective information with objective results has not always been appropriate ${ }^{(5)}$. Combining subjective and objective information allows a more accurate evaluation of nasal function, helping treatment decision-making and allowing better monitoring of diseases of the upper airways ${ }^{(6)}$.

The medical literature has focused on presentation of the available techniques for evaluation of nasal function and only a few studies have compared the practice with the existing methods

(7). Given the scarcity of such information, we describe and compare in this review the most used techniques and present options for daily medical practice. 


\section{History}

The beginnings of functional diagnostic rhinology go back to 1894 and 1895, when the Dutch scientist Hendrik Zwaardemaker, who invented the olfactometer, stimulated by the studies of Professor Franciscus Cornelis Donders, ophthalmologist at the University of Utrecht, recommended holding a refrigerated metal plate under the nose during exhalation to estimate the degree of airflow obstruction from the relative amounts of condensed vapour ${ }^{(8)}$. This technique was popularized by Glatzel and became known as the Glatzel Mirror (GM).

\section{Objective airway testing}

There is a wide variety of objective tests to assess nasal function. These use values indicative of nasal patency, thus facilitating medical practice. In surgical intervention, the objective values can predict satisfaction of patients undergoing septal surgery. For example, pre-operative normal values of peak nasal inspiratory flow (PNIF) can be a marker for poor surgical outcome ${ }^{(9)}$. Some methods, such as rhinomanometry, acoustic rhinometry, and PNIF, are well described techniques ${ }^{(10)}$ and their reference values have been established for different populations ${ }^{(11-13)}$. Nevertheless, studies on the methods applied for objective assessment of upper airways are necessary for standardization of the techniques and reference values considering different populations, genders, and age groups.

\section{Classification}

Objective tests can be divided into anatomical (e.g., acoustic rhinomanometry) and functional (rhinomanometry, PNIF) tests ${ }^{(14)}$.

\section{Acoustic rhinometry}

Acoustic rhinometry is an ultrasound technique that evaluates nasal patency and makes it possible to determine the cross-sectional area at any point between the nostril and nasopharynx.

Nasal volume between two points of the nasal cavity can also be calculated.

The technique is based on the analysis of sound reflected by the nasal cavities in response to an incidental sound wave. Incident and reflected nasal cavity sound waves are detected by a microphone and signals are conducted to a computer program, which generates a graph of the area as a function of the distance from the nostril ${ }^{(10)}$. The derivation of the measures from the reflected sound waves requires complex mathematical transformation as well as several theoretical assumptions. Nevertheless, such measures correlate well with nasal physiological measures and the nasal volume obtained by imaging techniques, such as computed tomography, magnetic resonance imaging, and rhinomanometry ${ }^{(15)}$. The AR technique was validated by comparing the results with PNIF measurements, as well as by its correlation with subjective symptoms of nasal obstruction and reversible congestion of the nasal mucosa ${ }^{(16)}$.
Acoustic rhinometry is not suitable for home monitoring and requires the use of relatively expensive equipment. However, it provides accurate and reproducible results, requires minimal patient cooperation, and can be used in children ${ }^{(17)}$.

\section{Rhinomanometry}

Rhinomanometry is a more sensitive and specific technique when compared with acoustic rhinometry. Modern rhinomanometers consist of two transducers, one that measures nasal airflow and another that measures differences in nasal pressure. Based on these measurements, the rhinomanometer calculates the resistance of the transnasal airway or, more simply, how difficult it is to breathe through the nose. Consecutive measurements of airflow and transnasal pressure are used to calculate the nasal resistance $(\mathrm{NR}=\mathrm{DP} / \mathrm{V}$, where $\mathrm{NR}=$ nasal resistance, $\mathrm{DP}$ $=$ differential pressure between the atmospheric pressure and the rhinopharynx, and V = transnasal airflow). Thus, rhinomanometry determines the relationship between transnasal pressure and flow. These values are plotted on a graph to determine nasal resistance. Some devices express the nasal conductance, which can be determined by dividing the differential pressure by the nasal resistance ${ }^{(18)}$. Active and passive anterior rhinomanometry or posterior rhinomanometry can be used. The Standardization Committee on Objective Assessment of the Nasal Airway suggests the use of active anterior rhinomanometry ${ }^{(10)}$.

Rhinomanometry is a well-described method with physiological measures established for various populations ${ }^{(10)}$. However, the measurements require patient cooperation and coordination. The rhinomanometric measurement can be carried out in preschool children and toddlers as young as 2 years old. It is dependent substantially on the psychomotor maturation, which is lower in younger children ${ }^{(18)}$. As for acoustic rhinometry, rhinomanometry requires an operator with technical skills, and the equipment is relatively expensive and is not portable ${ }^{(19)}$.

\section{Peak nasal flow}

Peak flow can be measured during inspiration or expiration. Of these measurements, peak nasal inspiratory flow (PNIF) is the best technique for monitoring, and has been validated in clinical trials. The fact that flow values are affected by lower airways was considered a limitation of this technique ${ }^{(20)}$. Currently, the concept of a single disease of the airways has changed this view, and the impact of the lower airways on the values obtained by tests that assess upper airway injury is now taken into consideration in the study of nasal function ${ }^{(21)}$.

\section{Peak nasal inspiratory flow}

PNIF measures the airflow penetrating the nasal cavity during forced nasal inspiration. Testing is performed in the standing ${ }^{(13)}$ 
Table 1. Characteristics of the most frequently used tests for assessment of nasal patency.

\begin{tabular}{|c|c|c|c|c|}
\hline & Acoustic rhinometry & Rhinomanometry & PNIF & Nasal spirometry \\
\hline Definition & Ultrasound device & $\begin{array}{l}\text { Transducers that measure } \\
\text { nasal airflow and differen- } \\
\text { ces in nasal pressure }\end{array}$ & $\begin{array}{l}\text { Plastic device with a scale } \\
\text { to measure the airflow cou- } \\
\text { pled to a nasal mask }\end{array}$ & $\begin{array}{l}\text { Conventional spirometer } \\
\text { with a plastic nasal adaptor }\end{array}$ \\
\hline Measurement & $\begin{array}{l}\text { Cross section and volume } \\
\text { between two points of the } \\
\text { nasal cavity }\end{array}$ & $\begin{array}{l}\text { Nasal resistance and con- } \\
\text { ductance }\end{array}$ & $\begin{array}{l}\text { Volume of air obtained per } \\
\text { minute during maximal } \\
\text { inspiration }\end{array}$ & $\begin{array}{l}\text { Volume of air expired per } \\
\text { minute through the nostrils }\end{array}$ \\
\hline $\begin{array}{l}\text { Relative cost of equip- } \\
\text { ment }\end{array}$ & $\begin{array}{l}\text { High } \\
\text { USD } 8,800\end{array}$ & $\begin{array}{l}\text { High } \\
\text { USD } 8,805\end{array}$ & $\begin{array}{l}\text { Low } \\
\text { USD } 176\end{array}$ & $\begin{array}{l}\text { High } \\
\text { USD 2,545 }\end{array}$ \\
\hline Operational difficulty & Requires skilled operator & Requires skilled operator & Simple technique & Requires skilled operator \\
\hline Patient cooperation & No & Yes & Yes & Yes \\
\hline $\begin{array}{l}\text { Reference values for } \\
\text { children }\end{array}$ & Yes & Yes & Yes & No \\
\hline
\end{tabular}

USD: U.S. dollar.

Information about the relative cost of the apparatus is given in U.S. dollars, for the following devices: Eccovision - Acoustic Rhinometer;

Rhinomanometer 300; In-check - inspiratory flow meter - Clement Clarke; and KOKO Spirometer.

or seated ${ }^{(12)}$ position, and the highest value reached in three breaths is the value considered. PNIF has been inversely correlated with nasal resistance measured by rhinomanometry. As reported previously, a moderate correlation was found between the results obtained by anterior rhinomanometry and PNIF for 22 patients with allergic rhinitis ${ }^{(22)}$.

The values obtained by PNIF are reproducible and related to the signs of rhinitis, as determined by clinical examination ${ }^{(23)}$. However, PNIF provides information that is qualitatively different from that provided by symptom scores. Indeed, in a previous study with children and adolescents, PNIF results showed weak correlation with the clinical symptoms reported by patients ${ }^{(24)}$. Another concern is related to relatively small changes in nasal resistance, which would not be reliably detected by PNIF, if compared with rhinomanometry ${ }^{(25)}$.

The PNIF is a well-validated method with baseline parameters specified for adults of different ethnic groups ${ }^{(12,26)}$. This test requires patient cooperation and coordination. Since the maneuvers are very simple, physiological measures have been obtained for children and adolescents in populations including those of Brazil (13) and Greece ${ }^{(27)}$.

PNIF requires portable equipment of less complexity and lower cost. It is suitable for epidemiological studies and home monitoring ${ }^{(23,28)}$ and may be useful in clinical and surgical follow-up of patients with nasal obstruction ${ }^{(10)}$.

\section{Nasal spirometry}

Nasal spirometry is performed using a slightly modified spirometer, resulting in a relatively higher cost. The mouthpiece is removed from the conventional spirometer and a plastic nasal adapter, similar to that used in acoustic rhinometry, is then connected. The spirometer measures the vital capacity (VC) and calculates the volume of air exhaled through the nostrils.

The correlation of nasal spirometry with rhinomanometry has been demonstrated, as reported by a previous study involving both healthy adults and adults diagnosed with nasal obstruction caused by septal deviation ${ }^{(2)}$. This method may be useful for selecting patients for septal surgery and for the postoperative follow-up ${ }^{(29)}$.

Table 1 presents the main characteristics of the tests commonly used in medical practice.

\section{Other methods}

\section{Optical rhinometry}

Optical rhinometry is also known as rhinostereometry and allows the direct, real-time measurement of changes in swelling of the nasal mucosa by external measurement. The measurement is carried out with monochromatic near-infrared light. Changes in the nasal mucosa are displayed and recorded ${ }^{(30)}$. 


\section{Odiosoft-Rhino}

The odiosoft-Rhino (OR) is a recently developed method that uses acoustic analysis to assess nasal patency. The OR is a portable device that consists of a computer and a microphone and is provided with a software program to calculate the frequency and intensity of the sound waves in the nasal cavity ${ }^{(31)}$.

Further studies are required to determine the viability of these techniques. For their application in clinical practice, the cost of the equipment and the quality of the information obtained must be considered.

Other methods to assess the nasal function have received less emphasis in the literature and will not be discussed in this review.

\section{Concluding remarks}

Nasal airflow is determined by a complex anatomical structure, providing large variations of nasal patency ${ }^{(1)}$. The combination of data obtained on clinical examination with objective values provides more precise information on nasal function ${ }^{(13)}$.
Objective values are desirable in medicine, especially in rhinology. The choice of the technique to evaluate nasal function depends on the conditions of each health service. Rhinomanometry, acoustic rhinometry and peak nasal inspiratory flow are the most studied techniques and their efficiency, accuracy and reproducibility have been demonstrated. The peak nasal inspiratory flow has been noted for its portability, low cost, and easy implementation and interpretation of results. Given that this method provides reliable information about nasal function for research and management of patients, its use may be considered in medical practice.

\section{Authorship contribution}

CC contributed in analysis and interpretation on data and drafting of the manuscript, whereas CRA and Cl participated in conception and design of the study and revised the article.

\section{Conflict of interest}

None to declare.

\section{References}

1. Gertner R, Podoshin L, Fradis M. A simple method of measuring the nasal airway in clinical work. J Laryngol Otol. 1984; 98: 351355.

2. Min YG, Jung HW, Kim CS. Prevalence study of nasal septal deformities in Korea: results of a nation-wide survey. Rhinology. 1995; 33: 61-65.

3. Hanif J, Jawad SS, Eccles R. A study to assess the usefulness of a portable spirometer to quantify the severity of nasal septal deviation. Rhinology. 2003; 41: 11-15.

4. Gleeson MJ, Youlten LJ, Shelton DM, Siodlak MZ, Eiser NM, Wengraf CL. Assessment of nasal airway patency: a comparison of four methods. Clin Otolaryngol Allied Sci. 1986; 11: 99-107.

5. André RF, Vuyk HD, Ahmed A, Graamans K, Nolst Trenité GJ. Correlation between subjective and objective evaluation of the nasal airway. A systematic review of the highest level of evidence Clin Otolaryngol. 2009; 34: 518-525.

6. Eccles R. Is a normal range of nasal function beyond the reach of rhinologists? Am J Rhinol. 2006; 20: 205.

7. Gleeson MJ, Youlten LJ, Shelton DM, Siodlak $M Z$, Eiser NM, Wengraf CL. Assessment of nasal airway patency: a comparison of four methods. Clin Otolaryngol Allied Sci. 1986; 11: 99-107.

8. Noyons AKM. Hendrik Zwaardemaker: 18571930. Am J Psychol. 1931; 43: 3.

9. Holmstrom M. The use of objective measures in selecting patients for septal surgery. Rhinology. 2010; 48: 387-393.
10. Clement PA, Gordts F. Standardisation Committee on Objective Assessment of the Nasal Airway, IRS, and ERS. Consensus report on acoustic rhinometry and rhinomanometry. Rhinology. 2005; 43: 169179.

11. Nathan RA, Eccles R, Howarth PH, Steinsvåg SK, Togias A. Objective monitoring of nasal patency and nasal physiology in rhinitis. J Allergy Clin Immunol. 2005; 115(3 Suppl 1): S442-459.

12. Ottaviano G, Scadding GK, Coles S, Lund VJ. Peak nasal inspiratory flow: normal range in adult population. Rhinology. 2006; 44 32-35.

13. Ibiapina CC, Andrade CR, Camargos PA, Alvim CG, Cruz AA. Reference values for peak nasal inspiratory flow in children and adolescents in Brazil. Rhinology. 2011; 49: 304-308.

14. Brazelton TB 3rd, Watson KF, Murphy M, Al-Khadra E, Thompson JE, Arnold JH. Identification of optimal lung volume during high-frequency oscillatory ventilation using respiratory inductive plethysmography. Crit Care Med. 2001; 29: 2349-2359.

15. Hilberg O, Pedersen OF. Acoustic rhinometry: recommendations for technical specifications and standard operating procedures. Rhinol Suppl. 2000; 16: 3-17.

16. Kjaergaard T, Cvancarova M, Steinsvåg SK. Relation of nasal air flow to nasal cavity dimensions. Arch Otolaryngol Head Neck Surg. 2009; 135: 565-570.

17. Haavisto LE, Sipilä Jl. Acoustic rhinometry in children: some practical aspects and influence of age and body surface area on results. Am J Rhinol. 2008; 22: 416-419.

18. Zapletal A, Chalupová J. Nasal airflow and resistance measured by active anterior rhinomanometry in healthy children and adolescents. Pediatr Pulmonol. 2002; 33 : 174-180.

19. Cole P, Fenton RS. Contemporary rhinomanometry. J Otolaryngol. 2006; 35: 83.

20. Chung SK, Son YR, Shin SJ, Kim SK. Nasal airflow during respiratory cycle. Am J Rhinol. 2006; 20: 379-384.

21. Giancarlo O, Valerie JL, Stuart C, Alberto S, Glenis K. Scadding. Does peak nasal inspiratory flow relate to peak expiratory flow? Rhinology. 2008; 46: 200-203.

22. Holmström M, Scadding GK, Lund VJ, Darby YC. Assessment of nasal obstruction. A comparison between rhinomanometry and nasal inspiratory peak flow. Rhinology. 1990; 28: 191-196.

23. Starling-Schwanz R, Peake HL, Salome CM, Toelle BG, Ng KW, Marks GB, et al. Repeatability of peak nasal inspiratory flow measurements and utility for assessing the severity of rhinitis. Allergy. 2005; 60: 795800.

24. Gomes Dde L, Camargos PA, Ibiapina Cda C, de Andrade CR. Nasal peak inspiratory flow and clinical score in children and adolescents with allergic rhinitis. Rhinology. 2008; 46: 276-280.

25. Clarke RW, Jones AS. The limitations of peak nasal flow measurement. Clin. Otolaryngol Allied Sci. 1994; 19: 502-504.

26. Bouzgarou MD, Saad HB, Chouchane A, Cheikh IB, Zbidi A. North African reference equation for peak nasal inspiratory flow. J 
Laryngol Otol. 2011; 28: 1-8

27. Papachristou A, Bourli E, Aivazi D, et al. Normal peak nasal inspiratory flow rate values in Greek children and adolescents Hippokratia. 2008; 12: 94-97.

28. Cho SI, Hauser R, Christiani DC Reproducibility of nasal peak inspiratory flow among healthy adults: assessment of epidemiologic utility. Chest. 1997; 112: 1547-1553.

29. Cuddihy PJ, Eccles R. The use of nasal spirometry as an objective measure of nasal septal deviation and the effectiveness of septal surgery. Clin Otolaryngol Allied Sci. 2003; 28: 325-330

30. Hallén H, Graf P. Evaluation of rhinostereometry compared with acoustic rhinometry. Acta Otolaryngol. 1999; 119: 921-924.

31. Tahamiler R, Alimoglu Y, Canakcioglu S. Comparison of Odiosoft-Rhino and rhinomanometry in evaluation of nasal patency. Rhinology. 2011; 49: 41-45.

\section{Cássio Ibiapina}

Departamento de Pediatria da Faculdade de Medicina da Universidade Federal de Minas Gerais

Avenida Professor Alfredo Balena 190 / Sala 267

30130-100 Belo Horizonte - Minas

Gerais

Brazil

Tel: +55-31-34099772

E-mail: cassioibiapina@terra.com.br

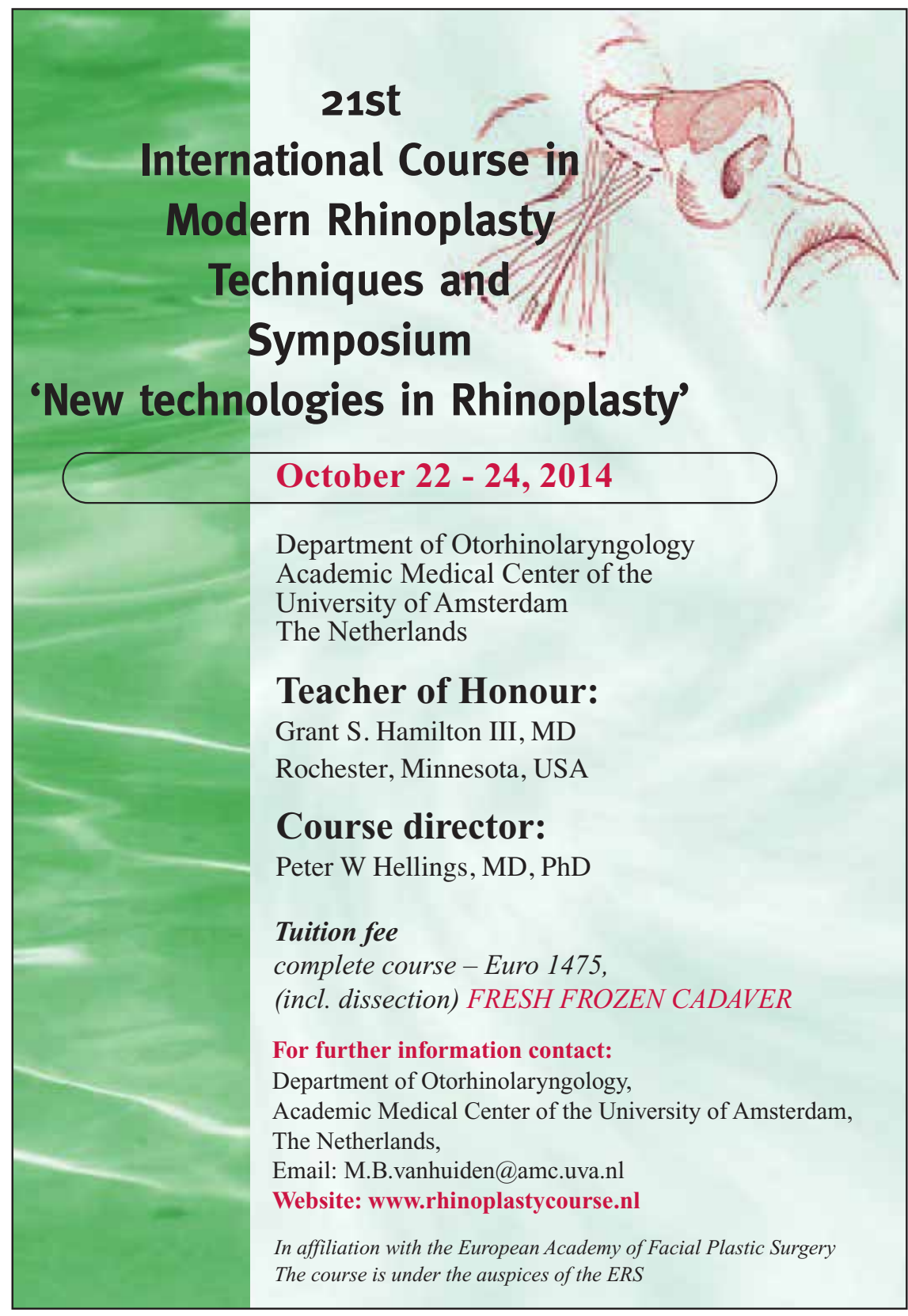

